\title{
New data on harmful effects of trans-fatty acids
}

\author{
Ginter $\mathrm{E}^{1}$, Simko $\mathrm{V}^{2}$ \\ Slovak Medical University, Bratislava, Slovakia. ginter.emil@mail.t-com.sk
}

\begin{abstract}
Various margarines containing trans-fatty acids were marketed as being healthier because of the absence of cholesterol, suggesting to use margarine instead of butter. Fifteen years ago, research documented the grave health risk of trans-fats (T-fat). US FDA in 2015 finalized its decision that T-fat is not safe and set a three-year time limit for complete removal of T-fat from all foods. The greatest danger from T-fat lies in its capacity to distort the cell membranes. The primary health risk identified for T-fat consumption is an elevated risk of coronary heart disease. T-fats have an adverse effect on the brain and nervous system. T-fat from the diet is incorporated into brain cell membranes and alter the ability of neurons to communicate. This can diminish mental performance. Relationship between T-fat intake and depression risk was observed. There is growing evidence for a possible role of T-fat in the development of Alzheimer's disease and cognitive decline with age (Fig. 1, Ref. 23). Text in PDF www.elis.sk.

KEY WORDS: cis-fatty acids, trans-fatty acids, hydrogenated fat, plant oil, margarine, membranes, heart disease, cognitive defects, Alzheimer's disease, food labeling.
\end{abstract}

More than 100 years have passed since Dr. Wilhelm Normann filed a patent on "Process for Converting Unsaturated Fatty Acids or their Glycerides into Saturated Compounds" at the British Patent Office. Dr. Normann could not have predicted that his invention of converting natural vegetable oil into solid fat could result in a major health problem.

The food industry eagerly started to market trans-fat (T-fat) because of its convenience: fat in a solid form is easier to package and artificial glycerides can be stored longer. For many decades, the households and food preparers in the world were flooded with millions of tons of various margarines deceptively marketed as being healthier because of the absence of cholesterol, suggesting to use margarine instead of butter. A major change in nutritional understanding of fat came only about 15 years ago when research documented the grave health risk of T-fat. In the USA the Food and Drug Administration (FDA) in 2015 finalized its decision that T-fat is not generally recognized as safe and set a three-year time limit for complete removal of T-fat from all processed foods.

The major players in the food industry all over the world showed to be resistant to change. It took several years for US nutritionists to succeed in forcing mandatory food labelling that includes a statement on T-fat. A statement declaring that a product contains no trans-fat, however still allows the presence of a small amount of this artificial fat. Additionally, the food industry has pressed to exempt from removing T-fat in their products including for example shortening, pie crust, brownies, peanut butter

${ }^{1}$ Slovak Medical University, Bratislava, Slovakia (emeritus), and ${ }^{2}$ State University of New York, Downstate Medical Center at Brooklyn, USA

Address for correspondence: E. Ginter, RND, DSc, Racianska 17, SK83102 Bratislava, Slovakia.
Different structure of cis- and trans-fatty acids

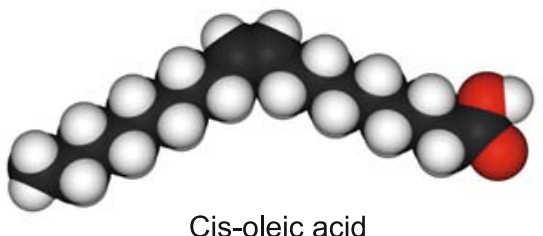

Cis-oleic acid



Trans-elaidic acid

Fig. 1. Different structures of cis- and trans-fatty acids.

and microwave popcorn. The ban on T-fat has to mean absolutely zero trans-fat.

The purpose of this review is to highlight the recent data on health risk posed by T-fat. T-fat accounts for about 1-2\% of energy in the European and North American diets. Hydrogenated oils contain a large proportion of T-fat. The major industrially produced trans-fatty acids in the food supply are elaidic acid isomers (Fig. 1).

\section{Trans-fatty acids and membranes}

The greatest danger from T-fat lies in its capacity to distort the cell membranes. Just consider the substantial spatial change in the fatty acid molecule altered by hydrogenation. The fluidity 
of membranes determines the extent to which molecules can be transported and signals can be transmitted through the membrane. Membrane fluidity is a function of its fatty acid and cholesterol content. Trans-fatty acid chains may disorder the membrane phospholipids and influence the fluidity of the membranes. This has wide implications for the body systems and functions, including heart disease and brain function. Persons who eat large amounts of foods containing T-fat, have been found with cell membranes that contain up to 20 percent T-fat. Trans-fatty acids cannot be used to produce useful mediators because the molecules have unnatural shapes that are not recognized by enzymes such as cyclooxygenase and lipoxygenase.

\section{Coronary heart disease}

The primary health risk identified for T-fat consumption is an elevated risk of coronary heart disease (CHD). Metabolic studies have shown that T-fat has adverse effect on blood lipid levels, namely by increasing LDL-cholesterol while decreasing HDL-cholesterol. A comprehensive review published in 2006 (1) concluded that "On a per-calorie basis, trans-fats appear to increase the risk of CHD more than any other macronutrient, conferring a substantially increased risk at low levels of consumption (1 to 3 $\%$ of total energy intake)”.

A meta-analysis related to the risk posed by T-fat was recently published (2). Total T-fat intake was associated with increased all-cause and CHD mortality rates. Reliable and strong positive associations between T-fat intake and CHD mortality, consistent with several previous systematic reviews and meta-analyses (3, 4) were found. The risk of heart disease is mediated via blood lipids and pro-inflammatory processes (5-8). The $2 \%$ increase in energy from T-fat is associated with about $30 \%$ increase in CHD mortality. The consumption of T-fat increases plasma activity of cholesteryl ester transfer protein, the main enzyme for the transfer of cholesterol esters from HDL to LDL and VLDL cholesterol. This increased activity may explain the drop in the levels of HDL and the rise in the levels of LDL and VLDL cholesterol seen with intake of T-fat (9). More recent reports confirm the detrimental effect of T-fat on heart health $(10,11)$.

\section{Cognitive disorders and Alzheimer's disease}

The brain is a fatty organ, comprising about 70 percent fat. T-fat from the diet is incorporated into brain cell membranes, including the myelin sheath that insulates neurons, playing a role in the sending of communication signals. Thus, T-fat may alter the ability of neurons to communicate. This can diminish mental performance.

Recently published review on the role of saturated fat and Tfat in dementia concluded that prospective studies indicate relationships between intakes of saturated fat and T-fat and the risk of cognitive disorders (12). Morris et al (13) related fat consumption to a 6-year change in cognitive function among 2,560 participants in Chicago. A diet high in saturated fat or T-fat may be associated with cognitive decline among older persons. Prospective cohort study of 12,059 Spanish university graduates, initially free of de- pression, found a detrimental relationship between T-fat intake and depression risk (14). A strong relation between dietary T-fat intake and self-reported behavioral aggression and irritability was also observed.

The prevalence of Alzheimer's disease (AD) increases exponentially with age. There is growing evidence for possible dietary risk factors, e.g. T-fat, in the development of $\mathrm{AD}$ and cognitive decline with age (15). Morris et al. (16) performed clinical evaluations on community residents aged over 65 , who were unaffected by $\mathrm{AD}$ at baseline. After a mean follow-up of 3.9 years, intake of T-fat was positively associated with risk of AD; the top 80 percent in T-fat consumption had four times the risk of developing AD than the 20 percent with the lowest T-fat consumption. These data are consistent with increased membrane phospholipid degradation in $\mathrm{AD}$ brain (17).

Several lines of evidence support the theory that an elevated blood cholesterol level is related to the development of AD. A study of 444 Finnish men found that an elevated blood cholesterol level in midlife was associated with 3 times the risk of developing $\mathrm{AD}$ in late life (18).

\section{Diabetes}

Although there is some support from observational and experimental studies for the hypothesis that high intake of T-fat may increase the risk for type 2 diabetes (19), inconsistencies across studies and methodological problems make it premature to draw definitive conclusions at this time. More experimental research in humans is needed to further address this question. More convincing are experiments in monkeys where T-fat consumption induced obesity and increased the risk of diabetes (20). Recently, reports were published on the trans-palmitoleic acid inducing diabetes in man $(21,22)$.

\section{Obesity}

A 6-year experiment revealed that monkeys fed a T-fat diet gained $7.2 \%$ of their body weight, as compared to $1.8 \%$ for monkeys on a mono-unsaturated fat diet (23). While in the popular media obesity is frequently linked to T-fat, there is not a strong scientific consensus associating T-fat and obesity in people.

\section{Cancer}

There is no scientific consensus that consumption of T-fat significantly increases cancer risk. The American Cancer Society states that a relationship between T-fat and cancer has not been determined.

\section{Conclusion}

The invention of fat hydrogenation leading to T-fat was considered a major technical breakthrough. Food industry enthusiastically accepted the mass production of a convenient form of artificially modified fat. Unlike the liquid unsaturated fatty acid 
vegetable oil, prone to oxygen-induced rancidity, hydrogenated fat in multiple modifications of margarine was promoted because the fat is solid and easier to store for a prolonged period. Because of its profitability, over the decades, enormous amounts of hydrogenated fat were fed to world populations, claiming a (false) benefit of promoting health, because margarines did not contain cholesterol. People were led to believe that margarine was healthier than butter. Critical research in the past 15 years reversed the tide, documenting health risk of hydrogenated fat and need to save thousands of lives. Food industry giants are suddenly exposed to a dramatic change in their production lines. No wonder they do their best to postpone the complete ban on hydrogenated fat. Scientific evidence is firmly in the best interest of public health.

\section{References}

1. Mozaffarian D, Katan MB, Ascherio A et al. Trans fatty acids and cardiovascular disease. N Engl J Med 2006; 354: 1601-1613.

2. de Souza RJ, Mente A, Maroleanu A et al. Intake of saturated and trans unsaturated fatty acids and risk of all cause mortality, cardiovascular disease, and type 2 diabetes: systematic review and meta-analysis of observational studies. BMJ 2015; 351: h3978.

3. Bendsen NT, Christensen R, Bartels EM, Astrup A. Consumption of industrial and ruminant trans fatty acids and risk of coronary heart disease: a systematic review and meta-analysis of cohort studies. Eur J Clin Nutr 2011; 65: 773-783.

4. Mozaffarian D, Aro A, Willett WC. Health effects of trans-fatty acids: Experimental and observational evidence. Eur J Clin Nutr 2009; 63: S5-S21

5. Mauger JF, Lichtenstein AH, Ausman LM, et al. Effect of different forms of dietary hydrogenated fats on LDL particle size. Am J Clin Nutr 2003; 78: 370-375.

6. Baer DJ, Judd JT, Clevidence BA, Tracy RP. Dietary fatty acids affect plasma markers of inflammation in healthy men fed controlled diets: a randomized crossover study. Am J Clin Nutr 2004; 79: 969-973.

7. Libby P, Ridker PM, Hansson GK. Inflammation in atherosclerosis: from pathophysiology to practice. J Am Coll Cardiol 2009; 54: 2129-2138.

8. Mozaffarian D, Rimm EB, King IB, Lawler RL, McDonald GB, Levy WC. Trans fatty acids and systemic inflammation in heart failure. Am J Clin Nutr 2004; 80: 1521-1525.

9. Ascherio A, Katan MB, Zock PL et al. Trans fatty acids and coronary heart disease. N Engl J Med 1999; 340: 1994-1998.
10. Brouwer IA, Wanders AJ, Katan MB. Trans fatty acids and cardiovascular health: research completed ? Eur J Clin Nutr 2013; 67: 541-547.

11. Fuster V. Global burden of cardiovascular disease time to Implement feasible strategies and to monitor results. J Am Coll Cardiol 2014; 64: 520-522.

12. Barnard ND, Bunner AE, Agarwal U. Saturated and trans fats and dementia: a systematic review. Neurobiol Aging 2014; 35 (Suppl 2): 65-73.

13. Morris C, Bienias JL et al. Dietary fat intake and 6-year cognitive change in an older biracial community population. Neurology 2004; 62: 1573-1579.

14. Sánchez-Villegas A, Verberne L, De Irala $\mathbf{J}$ et al. Dietary fat intake and the risk of depression: The SUN Project. PLoS ONE 2011; 6 (1): e16268.

15. Menaa F, Menaa A, Menaa B, Tréton J. Trans-fatty acids, dangerous bonds for health? A background review paper of their use, consumption, health implications and regulation in France. J Nutr 2013; 52:1 289-1302.

16. Morris MC. The role of nutrition in Alzheimer's disease: epidemiological evidence. Eur J Neurol 2009; 16 (Suppl 1): 1-7.

17. Niu SL, Mitchell DC, Litman BJ. Trans fatty acid derived phospholipids show increased membrane cholesterol and reduced receptor activation as compared to their cis analogs. Biochemistry 2005; 44: 4458-4465.

18. Solomon A, Kivipelto M, Wolozin B et al. Midlife serum cholesterol and increased risk of Alzheimer's and vascular dementia three decades later. Dement Geriatr Cogn Disord 2009; 28: 75-80.

19. Odegaard AO, Pereira MA. Trans fatty acids, insulin resistance, and type 2 diabetes. Nutr Rev 2006; 64: 364-372.

20. Kavanagh K, Jones KL, Sawyer J et al. Trans fat diet induces abdominal obesity and changes in insulin sensitivity in monkeys. Obesity 2007; 15: 1675-1684.

21. Mozaffarian D, Cao H, King IB et al. Trans-palmitoleic acid, metabolic risk factors, and new-onset diabetes in U.S. adults: a cohort study. Ann Intern Med 2010; 153: 790-799.

22. Mozaffarian D, de Oliveira Otto MC, Lemaitre RN et al. Transpalmitoleic acid, other dairy fat biomarkers, and incident diabetes: the Multi-Ethnic Study of Atherosclerosis (MESA). Am J Clin Nutr 2013; 97: 854-861.

23. Kavanagh K, Jones KL, Sawyer J et al. Trans fat diet induces abdominal obesity and changes in insulin sensitivity in monkeys. Obesity 2007; 15: 1675-1684. 